\title{
Baseline and Post-exercise High-Sensitivity C-Reactive Protein Levels in Endurance Cyclists: The Indonesian North Coast and Tour de Borobudur 2017 Study
}

\author{
Mahalul Azam ${ }^{1,2, *}$, Susanti Lestari ${ }^{1}$, Sri Ratna Rahayu ${ }^{1}$, Arulita Ika Fibriana ${ }^{1}$, Budhi Setianto ${ }^{3}$, \\ Nyoman Suci Widyastiti ${ }^{4}$, Suhartono ${ }^{5}$, Hardhono Susanto ${ }^{6}$, Martha Irene Kartasurya ${ }^{7}$, \\ Udin Bahrudin $^{8}$, Thijs Eijsvogels ${ }^{9}$
}

\begin{abstract}
${ }^{1}$ Department of Public Health, Faculty of Sport Sciences, Universitas Negeri Semarang, Jl. Sekaran, Gunungpati, Semarang, Indonesia ${ }^{2}$ Doctoral Program in Medicine and Health Sciences, Faculty of Medicine, Universitas Diponegoro, Jl. Imam Bardjo SH No. 5, Semarang, Indonesia ${ }^{3}$ Department of Cardiology and Vascular Medicine, Faculty of Medicine, Universitas Indonesia, J1. Letjen S. Parman Kav 87, Slipi, Jakarta, Indonesia ${ }^{4}$ Department of Clinical Pathology, Faculty of Medicine, Universitas Diponegoro, Jl. Doktor Sutomo No. 16, Semarang, Indonesia ${ }^{5}$ Department of Environmental Health, Faculty of Public Health, Universitas Diponegoro, Jl. Prof. Soedarto SH, Tembalang, Semarang, Indonesia ${ }^{6}$ Department of Anatomy, Faculty of Medicine, Universitas Diponegoro, Jl. Prof. Soedarto SH, Tembalang, Semarang, Indonesia ${ }^{7}$ Department of Public Health Nutrition, Faculty of Public Health, Universitas Diponegoro, Jl. Prof. Soedarto SH, Tembalang, Semarang, Indonesia ${ }^{8}$ Department of Cardiology and Vascular Medicine, Faculty of Medicine, Universitas Diponegoro, Jl. Doktor Sutomo No. 16, Semarang, Indonesia ${ }^{9}$ Department of Physiology, Radboud University Medical Center, Geert Grooteplein Zuid 30, Netherlands
\end{abstract}

*Corresponding author. E-mail: mahalul.azam@mail.unnes.ac.id

Received date: Sep 24, 2018; Revised date: Oct 25, 2018; Accepted date: Nov 21, 2018

\section{Abstract}

$\mathrm{B}$ ACKGROUND: Inflammation plays an important role in the atherosclerotic process. High-sensitivity C-reactive-protein (hs-CRP) is commonly used as inflammatory biomarker. It is well known that regular physical activity lowers hs-CRP levels, while prolonged exercise induces hs-CRP elevations. However, the relationship of training and exercise characteristics with hs-CRP levels remains not well elucidated. We evaluated baseline and post-exercise hs-CRP levels and its association with training and exercise characteristics.

METHODS: Eighty-eight male endurance cyclists were involved. Demographic data, health condition and training characteristics were collected. Baseline and postexercise blood-samples were collected to determine hsCRP concentrations. A hs-CRP cut-off point of $3 \mathrm{mg} / \mathrm{L}$ was used. Blood-cell count and biochemical parameters were measured at baseline. Heart rate (HR) was measured during exercise.

RESULTS: Cyclists performed 7.3 hours (interquartilerange $(\mathrm{IQR})=5.4-7.5)$ of endurance exercise at intensity of $81.8 \%(\mathrm{IQR}=74.9-85.8)$. Cyclists with baseline hs$\mathrm{CRP} \geq 3 \mathrm{mg} / \mathrm{L}$ reported higher body mass, body mass index (BMI), waist-circumference and total-cholesterol. An increase in hs-CRP was following endurance exercise. Cyclists with any elevation of hs-CRP reported a higher BMI, HR during exercise and exercise intensity. Binary logistic regression analysis showed BMI $(\mathrm{OR}=1.24,95 \%$ $\mathrm{CI}=1.04-1.48)$ and cycling distance $(\mathrm{OR}=0.22,95 \% \mathrm{CI}$ $=0.06-0.76)$ were associated with post-exercise hs-CRP elevations.

CONCLUSION: Body mass, BMI, waist-circumference, total- and HDL-cholesterol are associated with baseline hsCRP, whereas BMI and cycling distance were associated with hs-CRP elevations. These findings suggest that anthropometry parameters and lipid levels attributed to baseline hs-CRP, while anthropometry parameters and cycling intensity attributed to post-exercise hs-CRP elevations.

KEYWORDS: C-reactive-protein, exercise, endurancecycling, inflammation, acute-phase-response

Indones Biomed J. 2019; 11(1): 91-9 


\section{Introduction}

Inflammation plays a pivotal role in the mechanism of atherosclerotic and is a risk factor for the development of coronary artery diseases (CAD) risk factor.(1) Highsensitivity $\mathrm{C}$ reactive protein (hs-CRP) is a common clinical biomarker to assess inflammation and is established as an independent predictor for CAD.(2) A systematic review reported that regular physical activity lowers resting hsCRP levels, however as an acute-phase response hs-CRP is elevated after exercise. $(3,4) \mathrm{CRP}$ and tumor necrosis factoralpha $(\mathrm{TNF}-\alpha)$ were significantly increased after crosscountry skiing tour (5), while no changes in interleukin (IL)-6 were observed. Another study reported that CRP levels were influenced by exercise capacity as assessed by a treadmill exercise test.(6)

Alongside with exercise-induced changes in hs-CRP, several cardiac injury markers such as creatine kinasemuscle/brain (CK-MB), cardiac troponin, and $\mathrm{N}$ terminal pro B-type natriuretic peptide (NT-proBNP) are known to increase as well.(7) There is still controversy whether these biomarker increases represent a deleterious effect or not. $(7,8)$ Previous studies concluded that exercise-induced inflammatory responses are related to muscle injury and muscle damage.(9-11) An evidence also reported that highly post-exercise hs-CRP and cardiac troponin elevations were related to sub-clinical CAD event. $(12,13)$

A previous study reported that baseline hs-CRP was associated with body mass index (BMI), daily life activity level and high-sensitive cardiac troponin T (hs-cTnT) level in subjects suspected of the CAD.(14) Hs-CRP elevated following an exercise test (ET), but was not related to the CAD, exercise time, metabolic equivalents (METs), STsegment depression, angina during ET, increase in heart rate, and increase in systolic blood pressure. Exercise-induced hs-CRP elevations are well-published (4-7), however, the relationship of training and exercise characteristics with hsCRP elevation remains unclear.

Cycling is a popular sports activities and has many health benefits. However, endurance cycling is characterized by prolonged exercise at a high intensity, which is likely to cause exercise-induced inflammation. The present study explored the relationship of training and exercise characteristics with baseline and post-exercise hsCRP levels among endurance cyclists. We hypothesized that anthropometric parameters i.e., body mass, BMI, and waist circumference, lipid levels i.e., total- and HDL- cholesterol, and training characteristics are associated with baseline
hs-CRP levels, while antropometric parameters and exercise intensity are associated with post-exercise hs-CRP levels among endurance cyclists.

\section{Methods}

\section{Study Population}

Ninety-two endurance cyclists of two Indonesian long distance cycling tours, i.e., 2017 Indonesia North Coast tour (NC) (http://ina-northcoast-cyclingtour.com) and 2017 Tour de Borobudur (TdB) (https://event.sambabikers.com), were recruited for this prospective observational study. A detailed description of participants recruitment is presented in Figure 1.

\section{Ethical Approval}

The study protocol conformed to the concepts of the Declaration of Helsinki and approved by the local Ethics Committee in the Faculty of Medicine, Diponegoro University - Dr. Kariadi General Hospital, Semarang, Indonesia, and informed consent was obtained from all participants. The study was also registered at Protocol and Registration and Results System under Clinicaltrial.gov identifier (NCT number) NCT03310450.

\section{Demographic Data and Blood Sampling}

One day before the cycling tour, all cyclists completed a questionnaire on their personal characteristics, training characteristics, and health conditions, including a medical history. After completing the questionnaire, a $10 \mathrm{~mL}$ venous blood sample was drawn from the antecubital vein. All measurements i.e., completing a post-exercise questionnaire, body weighing, and blood sampling were repeated in the same manner. Post-exercise blood sampling was taken immediately post-exercise (less than 5 minutes).

\section{Anthropometric Measurements}

We used common anthropometric measurements including waist and hip circumference $(\mathrm{cm})$, body mass $(\mathrm{kg}), \mathrm{BMI}(\mathrm{kg} /$ $\mathrm{m}^{2}$ ), and waist to hip ratio. Anthropometric measurements for waist and hip circumference, body mass, and height respectively measured using circumference measuring tape SECA 201®, weighing scale SECA $813 \AA$, and height scale SECA Bodymeter 206® (SECA Corp, Birmingham, UK).

\section{Heart Rate (HR)}

HR was monitored during exercise using a chest band HR monitor (Polar RC3 GPS $\AA$, Polar Corporation, Kempele, 


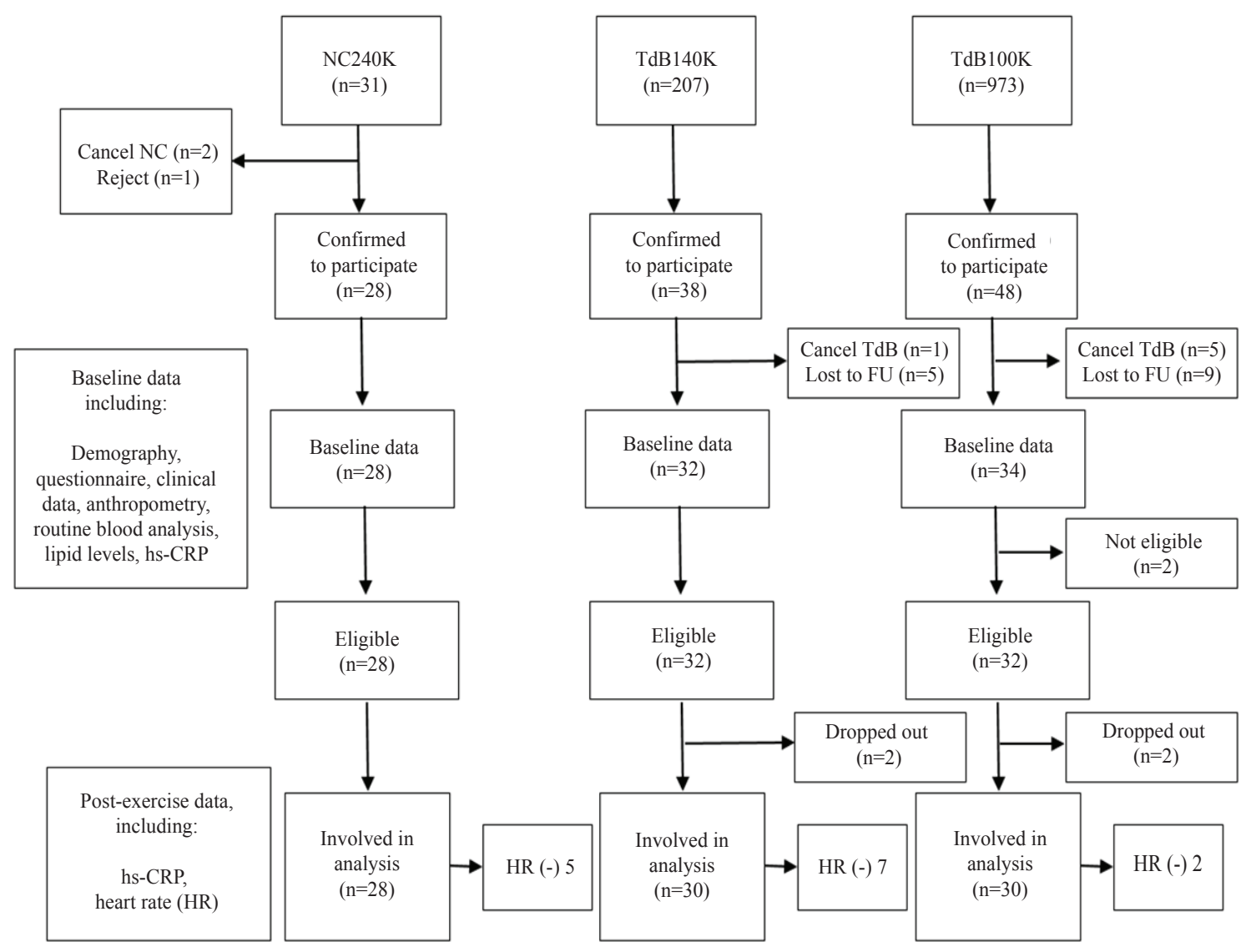

Figure 1. Participants recruitment flow diagram.

Finland). We determined mean HR as the average HR during cycling and peak HR as the highest HR during cycling. Maximal predicted heart rate $(\mathrm{HRmax}=208-0.7 *$ age $)$, and exercise intensity (Exercise intensity $=100 *$ mean HR/ HRmax) were calculated.(15).

\section{Laboratory Tests}

The blood samples $(10 \mathrm{~mL})$ taken before and immediately after exercise were analyzed in the laboratory. The whole blood sample for routine blood was analyzed on an automated blood cell counter (Sysmex Xn-350, Sysmex Corporation, Kobe, Japan). The other fractions of whole blood were collected in serum-gel vacutainer tubes and allowed to clot for 45 minutes. After centrifugation, the serum was aliquoted, frozen, and stored at $-80^{\circ} \mathrm{C}$ for future analysis. All analyses were conducted using the same calibration and setting to minimize variation. The hs-CRP was measured using a high-sensitivity CRP assay (CR120C, Calbiotech, El Cajon, USA). The assay detection limit was $0.02 \mathrm{mg} / \mathrm{L}$. A hs-CRP value of $3 \mathrm{mg} / \mathrm{L}$ was used as the cut-off point. $(14,16)$ Post-exercise hs-CRP elevation was determined by a positive delta hs-CRP $(\Delta \mathrm{hs}-\mathrm{CRP}=$ post-exercise hs-CRP level - baseline hs-CRP level). Biochemical parameters (i.e., hemoglobin, total cholesterol and HDL cholesterol) were analyzed using automated analyzer Cobas C-501 (Roche Diagnostics, Indianapolis, USA).

\section{Statistical Analysis}

All numeric data with a Gaussian distribution were reported as a mean \pm standard deviation (SD) and statistical significance was considered at a $p$-value $<0.05$. Statistical analyses were performed using the Statistical Package for the Social Sciences (IBM SPSS Statistics for Windows, Version 23.0, IBM Corp., New York, USA). The normality of the data distribution was examined by the KolmogorovSmirnov test. When the data demonstrated a non-Gaussian distribution, natural logarithmic transformation was applied. If the data remained not normally distributed after transformation, non-parametric statistics were used and data were presented as median with interquartile range.

A paired Student's t-test was used to test the significance of the differences between baseline and postexercise hs-CRP levels. Bivariate logistic regression analysis with enter method was used to determine parameters that 
were related to a baseline hs-CRP levels $\geq 3 \mathrm{mg} / \mathrm{L}$ and a post-exercise hs-CRP elevation. Based on our hypothesis and potential confounding factors, we included age, BMI, medical history (i.e., history of hypertension, dyslipidemia, diabetes mellitus, family history of CAD), systolic and diastolic blood pressure, blood cell count, total and HDL cholesterol, exercise duration, mean HR, peak HR and exercise intensity in our model as potential determinants to predict post-exercise hs-CRP elevation. Thereafter, all predictors with a $p$-value $<0.10$ were retained in the final regression model.

\section{Results}

\section{Subject Characteristics}

Cyclists completed the NC240K tour $(n=31)$, TdB140K $(n=207)$ and TdB100K $(n=973)$ in 2017. NC240K participants cycled for $240 \mathrm{~km}$ with a total elevation of 826 $\mathrm{m}$, in a sunny weather with an average temperature of $33^{\circ} \mathrm{C}$ $\left(28^{\circ}-41^{\circ} \mathrm{C}\right)$. TdB140K participants cycled for $140 \mathrm{~km}$, with a total elevation of $2754 \mathrm{~m}$, in a drizzle and mostly rainy weather, with an average temperature of $26^{\circ} \mathrm{C}\left(21^{\circ}-37^{\circ} \mathrm{C}\right)$. The TdB100K group cycled $100 \mathrm{~km}$, with a total elevation of $1117 \mathrm{~m}$, and had sunny weather with an average temperature of $30^{\circ} \mathrm{C}\left(28^{\circ}-34^{\circ} \mathrm{C}\right)$.
We recruited 92 male cyclists for this study, but $n=4$ athletes dropped out since they did not complete the postexercise examinations and were excluded from further analyses. The remaining 88 cyclists covered $240 \mathrm{~km}(\mathrm{n}=28)$, $140 \mathrm{~km}(\mathrm{n}=30)$ and $100 \mathrm{~km}(\mathrm{n}=30)$. Table 1 provides an overview of subject characteristics. CAD family history, HDL cholesterol levels, neutrophil count and resting HR, showed significant differences between the different cycling distance groups $(p<0.05)$. NC240K cyclists had a higher HDL cholesterol and lower neutrophil count and resting HR compared to the TdB140K and TdB100K cyclists. All other subject characteristics were comparable across groups.

Table 2 provides an overview of the training and exercise characteristics of the subjects. Training characteristics between groups were comparable. Due to the difference of cycling distance, we found differences in exercise duration, recovery $\mathrm{HR}$ and exercise intensity across groups $(p<0.05)$. Peak HR and mean HR did not differ across groups $(p>0.05)$.

\section{Baseline hs-CRP}

Baseline hs-CRP in NC240K cyclists had the lower levels $(2.6 \pm 2.24 \mathrm{mg} / \mathrm{L})$ than other groups $(\mathrm{TdB} 140 \mathrm{~K}=3.3 \pm 3.31$ $\mathrm{mg} / \mathrm{L} ; \mathrm{TdB} 100 \mathrm{~K}=3.0 \pm 3.23 \mathrm{mg} / \mathrm{L}$ ) (Table 1). Cyclists with baseline hs-CRP levels $\geq 3 \mathrm{mg} / \mathrm{L}(\mathrm{n}=24$, mean age $46.5 \pm 11.10$ years) had a higher body mass, BMI, waist

Table 1. Cyclist's characteristics based on touring groups.

\begin{tabular}{|c|c|c|c|c|c|}
\hline Variables & $\begin{array}{c}\mathrm{NC240K} \\
(\mathrm{n}=28)\end{array}$ & $\begin{array}{c}\text { TdB140K } \\
(\mathrm{n}=30)\end{array}$ & $\begin{array}{c}\text { TdB100K } \\
(\mathrm{n}=30)\end{array}$ & $\begin{array}{c}\text { Total } \\
(\mathrm{n}=\mathbf{8 8})\end{array}$ & $p$ \\
\hline Age (years old; mean \pm SD) & $43.3 \pm 9.33$ & $43.5 \pm 10.18$ & $49 \pm 13.70$ & $45.3 \pm 11.47$ & $0.090^{*}$ \\
\hline Height $(\mathrm{cm} ;$ mean \pm SD) & $167.2 \pm 5.02$ & $167.1 \pm 4.35$ & $167.3 \pm 4.5$ & $167.2 \pm 4.58$ & $0.969^{*}$ \\
\hline Body mass $(\mathrm{kg}$; mean $\pm \mathrm{SD})$ & $67.9 \pm 7.51$ & $68.5 \pm 9.10$ & $66.8 \pm 11.21$ & $67.7 \pm 9.36$ & $0.779^{*}$ \\
\hline $\mathrm{BMI}\left(\mathrm{kg} / \mathrm{m}^{2} ;\right.$ mean $\left.\pm \mathrm{SD}\right)$ & $24.2 \pm 2.26$ & $24.5 \pm 3.11$ & $23.7 \pm 3.60$ & $24.2 \pm 3.03$ & $0.653^{*}$ \\
\hline \multicolumn{6}{|l|}{ Medical history } \\
\hline Hypertension (n) & 4 & 3 & 6 & 13 & $0.549^{* *}$ \\
\hline Dyslipidemia (n) & 7 & 12 & 9 & 28 & $0.456^{* *}$ \\
\hline Diabetes mellitus (n) & 1 & 1 & 0 & 2 & $0.588^{* *}$ \\
\hline Family history of CAD (n) & 3 & 0 & 0 & 3 & $0.036^{* *}$ \\
\hline \multicolumn{6}{|l|}{ Lipid levels } \\
\hline Total cholesterol levels (mg/dL; mean $\pm \mathrm{SD}$ ) & $216.6 \pm 55.04$ & $208.1 \pm 27.13$ & $203.1 \pm 31.95$ & $209.1 \pm 39.45$ & $0.427^{*}$ \\
\hline HDL cholesterol levels (mg/dL; mean \pm SD) & $68.98 \pm 19.09$ & $52.1 \pm 13.9$ & $53.6 \pm 12.45$ & $58.0 \pm 16.97$ & $<0.001^{*}$ \\
\hline Neutrophil $\left(10^{6} / \mathrm{L}\right.$; mean $\left.\pm \mathrm{SD}\right)$ & $50.8 \pm 9.03$ & $51.8 \pm 7.94$ & $55.7 \pm 7.12$ & $52.8 \pm 8.23$ & $0.050^{*}$ \\
\hline Lymphocyte $\left(10^{6} / \mathrm{L} ;\right.$ mean $\left.\pm \mathrm{SD}\right)$ & $37.3 \pm 8.93$ & $36.7 \pm 7.7$ & $33.8 \pm 6.8$ & $35.9 \pm 7.9$ & $0.182^{*}$ \\
\hline Monocyte $\left(10^{6} / \mathrm{L} ;\right.$ mean $\left.\pm \mathrm{SD}\right)$ & $7.8 \pm 1.65$ & $7.8 \pm 1.40$ & $7.1 \pm 1.61$ & $7.6 \pm 1.57$ & $0.190^{*}$ \\
\hline Resting HR (bpm; mean $\pm \mathrm{SD}$ ) & $57.6 \pm 8.7$ & $63.2 \pm 9.3$ & $66.7 \pm 8.05$ & $62.6 \pm 9.3$ & $0.001^{*}$ \\
\hline Baseline hs-CRP (mg/L; mean \pm SD) & $2.6 \pm 2.24$ & $3.3 \pm 3.11$ & $3.0 \pm 3.23$ & $2.9 \pm 2.89$ & $0.645^{*}$ \\
\hline
\end{tabular}


Table 2. Training and exercise characteristics based on touring groups.

\begin{tabular}{|c|c|c|c|c|c|}
\hline Variables & $\begin{array}{c}\text { NC240K } \\
(n=28)\end{array}$ & $\begin{array}{c}\text { TdB140K } \\
(\mathrm{n}=30)\end{array}$ & $\begin{array}{c}\text { TdB100K } \\
(\mathrm{n}=\mathbf{3 0})\end{array}$ & $\begin{array}{l}\text { Total } \\
(\mathrm{n}=\mathbf{8 8})\end{array}$ & $p$ \\
\hline $\begin{array}{l}\text { Cycling distance in previous month } \\
(\mathrm{km} \text {; median (range)) }\end{array}$ & $897(205-1,360)$ & $495(180-1350)$ & $582(170-1,350)$ & $602(170-1,360)$ & $0.205^{* * *}$ \\
\hline \multicolumn{6}{|l|}{ Long-distance cycling participation } \\
\hline Yes (n) & $26(92.9 \%)$ & $21(70 \%)$ & $24(80 \%)$ & $71(80.7 \%)$ & $0.088^{* *}$ \\
\hline Never (n) & $2(7.1 \%)$ & $9(30 \%)$ & $6(20 \%)$ & $17(19.3 \%)$ & \\
\hline \multicolumn{6}{|l|}{ Exercise characteristics } \\
\hline Exercise duration (hours; median (range)) & $7.5(7.5-8.0)$ & $7.5(4.0-9.8)$ & $5.0(3.5-6.5)$ & $7.3(3.5-9.8)$ & $<0.001^{* * *}$ \\
\hline Recovery HR (bpm; (median (range)) & $80.5(57.0-133.0)$ & $91.0(59.0-168.0)$ & $94.0(73.0-113.0)$ & $90.0(57.0-168.0)$ & $<0.001^{* * * *}$ \\
\hline Mean HR (bpm; median (range)) & $140.0(104.0-165.0)$ & $133.0(94.0-160.0)$ & $141.0(96.0-180.0)$ & $140.0(94.0-180.0)$ & $0.151^{* * *}$ \\
\hline Peak HR (bpm; median (range)) & $168.0(128.0-196.0)$ & $180.8(122.0-229.0)$ & $172.5(116.0-233.0)$ & $173.5(116.0-233.0)$ & $0.075^{* * *}$ \\
\hline Exercise intensity (\%; median (range)) & $84.3(75.14-90.80)$ & $80.8(53.73-92.16)$ & $74.5(45.58-90.98)$ & $81.8(45.58-92.16)$ & $<0.001^{* * * *}$ \\
\hline Post-exercise hs-CRP (mg/L; mean $\pm \mathrm{SD})$ & $3.5 \pm 3.33$ & $4.5 \pm 2.86$ & $3.3 \pm 3.75$ & $3.8 \pm 3.34$ & $0.335^{*}$ \\
\hline
\end{tabular}

circumference, total cholesterol level and ratio of total cholesterol to HDL cholesterol (Table 3) compared to cyclists with baseline hs-CRP levels $<3 \mathrm{mg} / \mathrm{L}$ ( $\mathrm{n}=64$; mean age $44.9 \pm 11.66$ years). Alongside with baseline hs-CRP levels among cycling distance groups, Table 3 also showed that there was no difference in the proportion of the cycling distance groups categorized by a cut-off point of $3 \mathrm{mg} / \mathrm{L}$.

\section{Post-exercise hs-CRP}

A significant increase in hs-CRP levels i.e., $0.9 \mathrm{mg} / \mathrm{L}$ was found $(p=0.022)$ from baseline $(2.9 \pm 2.89 \mathrm{mg} / \mathrm{L})$ to postexercise $(3.8 \pm 3.34 \mathrm{mg} / \mathrm{L})$ in our study population (Figure 2 ). However, the exercise-induced increase in hs-CRP appeared to be different among subgroups. A significant increase in hs-CRP levels i.e., $0.9 \mathrm{mg} / \mathrm{L}$ was found in the $\mathrm{NC} 240 \mathrm{~K}$ group $(2.6 \pm 2.24 \mathrm{mg} / \mathrm{L}$ to $3.5 \pm 3.33 \mathrm{mg} / \mathrm{L}, p=0.020)$ and $1.1 \mathrm{mg} / \mathrm{L}$ in the TdB140K group $(3.3 \pm 3.31 \mathrm{mg} / \mathrm{L}$ to $4.5 \pm 2.86 \mathrm{mg} / \mathrm{L}$, $p=0.003$ ), but was not found in the TdB100K participants (3.0 $\pm 3.23 \mathrm{mg} / \mathrm{L}$ to $3.3 \pm 3.75 \mathrm{mg} / \mathrm{L}, p=0.960$ ).

Cyclists with post-exercise hs-CRP elevations ( $\mathrm{n}=58$, mean age $43.7 \pm 11.20$ years) had a higher BMI, higher HR during exercise, and higher exercise intensity (Table 3) compared to cyclists without post-exercise hs-CRP elevations ( $\mathrm{n}=30$; mean age $48.5 \pm 11.47$ years). NC240K and TdB140K participants had a higher prevalence of post-exercise hs-CRP elevations (i.e., $67.8 \%$ and $80 \%$ respectively) compared to $\mathrm{TdB} 100 \mathrm{~K}$ participants (50\%).

Binary logistic regression analysis showed that BMI (OR: 1.241, 95\% CI: 1.043-1.476); $p=0.015$ ) and cycling distance (OR: $0.217,95 \%$ CI: $0.062-0.758$ ); $p=0.017$ ) were the only parameters with a significant association with post-exercise hs-CRP elevation in our multivariable model $(\mathrm{r}=0.216, p=0.007)$. The other variables included in the analysis did not reach statistical significance and were therefore excluded from regression analysis as determinants of post-exercise hs-CRP elevation (Table 4).

\section{Discussion}

The present study revealed several interesting findings. First, we found that BMI, waist circumference, totaland HDL-cholesterol were significantly associated with baseline hs-CRP levels. Second, we found a significant increase in hs-CRP levels after prolonged exercise and its related to BMI and cycling distance. These findings indicate that anthropometry measurement and lipid profile were related to resting hs-CRP concentration, whereas, besides anthropometry, cycling intensity was related to elevated hsCRP as an acute phase response.

The predictors for baseline hs-CRP levels that were identified in the present study (i.e., BMI, waist circumference, total- and HDL-cholesterol) align with previous studies in this field of research for the subjects of general large population (17), female elderly (18) and diabetic patients (19). A recent study reported that IL-6 and hs-CRP concentrations were related to anthropometric parameters, such as BMI, waist to hip ratio, body adiposity index and neck circumference.(18) Another study reports that hs-CRP, white blood count and fibrinogen were associated with waist circumference, body mass, BMI, body adiposity index, waist/hip ratio and waist/height ratio. 
Table 3. Parameters based on baseline hs-CRP and post-exercise hs-CRP elevation.

\begin{tabular}{|c|c|c|c|c|c|c|}
\hline \multirow{2}{*}{ Variables } & \multicolumn{2}{|c|}{ Baseline hs-CRP } & \multirow{2}{*}{$p$} & \multicolumn{2}{|c|}{ Post-exercise hs-CRP elevation } & \multirow{2}{*}{$p$} \\
\hline & $\geq 3 \mathrm{mg} / \mathrm{L}(\mathrm{n}=24)$ & $<3 \mathrm{mg} / \mathrm{L}(\mathrm{n}=64)$ & & Yes $(n=58)$ & No $(n=30)$ & \\
\hline Age (years old; mean \pm SD) & $46.5 \pm 11.10$ & $44.9 \pm 11.66$ & $0.571^{*}$ & $43.7 \pm 11.20$ & $48.5 \pm 11.47$ & $0.064^{*}$ \\
\hline Body mass $(\mathrm{kg} ;$ mean $\pm \mathrm{SD})$ & $70.5 \pm 6.78$ & $66.7 \pm 10.00$ & $0.043^{*}$ & $66.6 \pm 8.98$ & $69.9 \pm 9.83$ & $0.115^{*}$ \\
\hline $\mathrm{BMI}\left(\mathrm{kg} / \mathrm{m}^{2} ;\right.$ mean $\left.\pm \mathrm{SD}\right)$ & $25.3 \pm 2.75$ & $23.7 \pm 3.06$ & $0.030 *$ & $25.1 \pm 3.56$ & $23.7 \pm 2.62$ & $0.029^{*}$ \\
\hline Waist circumference $(\mathrm{cm} ;$ mean $\pm \mathrm{SD})$ & $88.3 \pm 6.06$ & $84.1 \pm 8.93$ & $0.015^{*}$ & $84.4 \pm 8.20$ & $86.8 \pm 8.73$ & $0.210^{*}$ \\
\hline Hip circumference $(\mathrm{cm} ;$ mean $\pm \mathrm{SD})$ & $90.8 \pm 4.77$ & $88.6 \pm 7.45$ & $0.104^{*}$ & $88.5 \pm 6.80$ & $90.4 \pm 6.95$ & $0.233^{*}$ \\
\hline Waist-hip ratio & $0.97 \pm 0.062$ & $0.94 \pm 0.053$ & $0.084^{*}$ & $0.95 \pm 0.059$ & $0.96 \pm 0.051$ & $0.714^{*}$ \\
\hline Systolic blood pressure $(\mathrm{mmHg}$; mean $\pm \mathrm{SD})$ & $120 \pm 13.5$ & $122 \pm 13.8$ & $0.669^{*}$ & $120 \pm 12.8$ & $124 \pm 15.8$ & $0.178^{*}$ \\
\hline Diastolic blood pressure $(\mathrm{mmHg}$; mean $\pm \mathrm{SD})$ & $82 \pm 6.6$ & $80 \pm 7.7$ & $0.250^{*}$ & $79 \pm 7.3$ & $82 \pm 7.6$ & $0.179^{*}$ \\
\hline Neutrophil $\left(10^{6} / \mathrm{L} ;\right.$ mean $\left.\pm \mathrm{SD}\right)$ & $53.7 \pm 8.05$ & $52.5 \pm 8.34$ & $0.543^{*}$ & $53.5 \pm 8.58$ & $51.6 \pm 7.50$ & $0.312^{*}$ \\
\hline Lymphocyte $\left(10^{6} / \mathrm{L}\right.$; mean $\left.\pm \mathrm{SD}\right)$ & $35.5 \pm 8.24$ & $36.1 \pm 7.83$ & $0.740^{*}$ & $35.2 \pm 7.98$ & $37.4 \pm 7.68$ & $0.224^{*}$ \\
\hline Monocyte $\left(10^{6} / \mathrm{L} ;\right.$ mean $\left.\pm \mathrm{SD}\right)$ & $7.2 \pm 1.14$ & $7.6 \pm 1.68$ & $0.203^{*}$ & $7.5 \pm 1.66$ & $7.6 \pm 1.37$ & $0.714^{*}$ \\
\hline Resting HR (bpm; mean \pm SD) & $64.8 \pm 8.46$ & $61.8 \pm 9.64$ & $0.116^{*}$ & $62.6 \pm 9.38$ & $62.7 \pm 9.54$ & $0.989^{*}$ \\
\hline \multicolumn{7}{|l|}{ Medical history } \\
\hline Hypertension (n) & 6 & 7 & $0.097^{* *}$ & 6 & 7 & $0.097^{* *}$ \\
\hline Dyslipidemia (n) & 10 & 18 & $0.169^{* *}$ & 16 & 12 & $0.172^{* *}$ \\
\hline Diabetes mellitus (n) & 1 & 1 & $0.473^{* *}$ & 0 & 2 & $0.114^{* *}$ \\
\hline Family-history of CAD (n) & 2 & 1 & $0.179^{* *}$ & 2 & 1 & $0.179^{* *}$ \\
\hline Smoking (n) & 1 & 5 & $0.476^{* *}$ & 5 & 1 & $0.328^{* *}$ \\
\hline \multicolumn{7}{|l|}{ Lipid levels } \\
\hline Total cholesterol levels (mg/dL; mean \pm SD) & $222 \pm 35.18$ & $203 \pm 40.01$ & $0.038^{*}$ & $207 \pm 41.3$ & $213 \pm 35.8$ & $0.505^{*}$ \\
\hline HDL cholesterol levels (mg/dL; mean \pm SD) & $55.3 \pm 17.60$ & $58.9 \pm 16.75$ & $0.361^{*}$ & $58.4 \pm 16.81$ & $57.1 \pm 17.52$ & $0.743^{*}$ \\
\hline $\mathrm{TC}$ to $\mathrm{HDL}$ ratio & $4.4 \pm 3.62$ & $3.66 \pm 1.04$ & $0.010^{*}$ & $3.7 \pm 1.11$ & $4.00 \pm 1.17$ & $0.367^{*}$ \\
\hline $\begin{array}{l}\text { Average cycling distance in previous month } \\
(\mathrm{km} \text {; median (range)) }\end{array}$ & $675(214-1,220)$ & $585(170-1,360)$ & $0.715^{* * *}$ & $675(214-1,220)$ & $585(170-1,360)$ & $0.715^{* * *}$ \\
\hline \multicolumn{7}{|l|}{ Long-distance cycling experience } \\
\hline Yes (n) & $20(83.3 \%)$ & $51(79.7 \%)$ & $0.479^{* *}$ & $12(20.7 \%)$ & $5(16.7 \%)$ & $0.441^{* *}$ \\
\hline Never (n) & $4(16.7)$ & $13(20.3 \%)$ & & $46(79.3 \%)$ & $25(83.3 \%)$ & \\
\hline \multicolumn{7}{|l|}{ Exercise characteristics } \\
\hline Cycling distance NC $240 \mathrm{~K}(\mathrm{n})$ & $7(29.2 \%)$ & $21(32.8 \%)$ & & $19(32.7 \%)$ & $9(30 \%)$ & \\
\hline Cycling distance TdB 140K (n) & $9(37.5 \%)$ & $21(32.8 \%)$ & & $24(41.4 \%)$ & $6(20 \%)$ & \\
\hline Cycling distance TdB 100K (n) & $8(33.3 \%)$ & $22(34.4 \%)$ & & $15(25.9 \%)$ & $15(50 \%)$ & \\
\hline Exercise duration (hours; median (range)) & & & & $7.5(3.5-9.8)$ & $6.3(3.5-8.7)$ & $0.161^{* * *}$ \\
\hline Mean HR (bpm; median (range)) & & & & $140(94-180)$ & $134(96-158)$ & $0.008^{* * *}$ \\
\hline Peak HR (bpm; median (range)) & & & & $175(128-229)$ & $168(116-233)$ & $0.444^{* * *}$ \\
\hline Exercise intensity (\%; median (range)) & & & & $82.8(53.73-92.16)$ & $80.7(45.6-90.8)$ & $<0.001^{* * *}$ \\
\hline
\end{tabular}

(17) These findings suggest that anthropometry parameters are related to baseline hs-CRP and other inflammation biomarkers. We also found that BMI was associated to postexercise hs-CRP elevation as well. Inflammation is more prominent in individuals with CVD risk factors include high BMI. It is well known that obesity associated with inflammation through the mechanism of platelet activation (20) and lippoinflammation.(21)
A higher total cholesterol and lower HDL cholesterol was found in cyclists with baseline hs-CRP $\geq 3 \mathrm{mg} / \mathrm{L}$. It is well known that long-term exercise training increases HDL-cholesterol levels but decreases BMI, IL-6 and hsCRP levels.(22-24) So less trained individuals are expected to demonstrate higher resting concentrations of hs-CRP. $(22,25)$ Indeed, a Chinese study reported that hs-CRP and HDL cholesterol levels were inversely associated with 


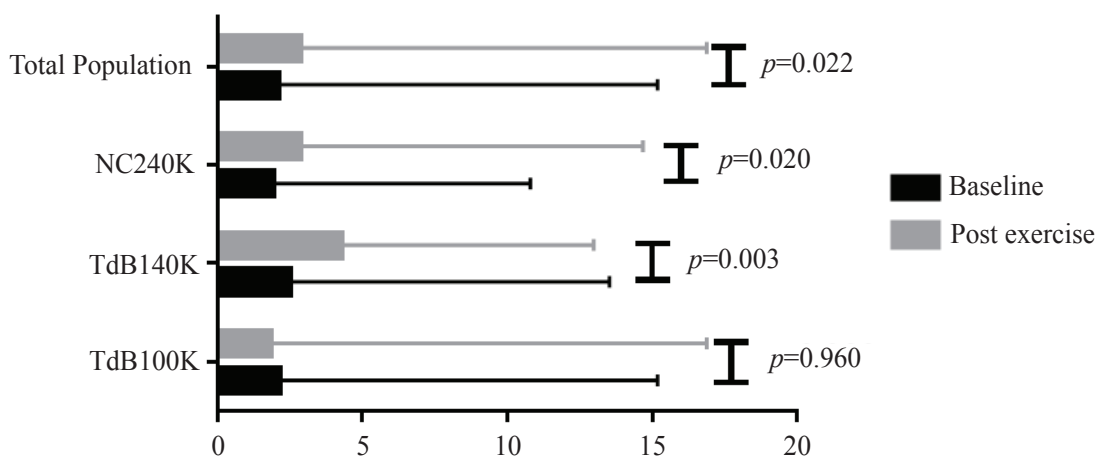

Figure 2. Baseline and post-exercise hs-CRP levels.

the dose of exercise session (23) and the dose of training intensity $(22,25)$. These studies concluded that the least trained individuals have higher hs-CRP and lower HDL cholesterol compared to the most trained individuals.(24) Another study in Austria reports that heavy workers tend to have better oxidation status, determined by total oxidant capacity and MDA levels compared to office workers. (26) The study in the United States of America and Brazil also concluded that higher physical activity levels tend to have lower hs-CRP levels. $(27,28)$ The previous studies concluded that the more intensity of exercise session the better status of hs-CRP levels and lipid profile. However, in this study based on touring groups, there were no significant differences in baseline hs-CRP levels, but the lipid levels remain significantly different. This condition can be explained that training habit characteristics between the groups were almost comparable, impacts on hs-CRP levels status accordingly (Table 3 ). The condition why lipid levels remain different between groups, leaving unclear explanation and further study must be conducted.

The current study also confirmed that exercise-induced hs-CRP elevations are common following prolonged cycling. Almost all groups have significantly different post-exercise and baseline hs-CRP levels, except TdB100K group (Figure $2)$. This finding may directly relate to exercise duration and intensity as TdB100K participants cycled for 5.0 (3.5-6.5) hours at $74.5 \%$ (45.58-90.98) of HRmax, whereas the other groups cycled longer and at a higher intensity (Table 2).

Exercise-induced hs-CRP elevation has been widely reported and attributed to the acute heavy physical activity. $(29,30)$ In response to heavy physical activity, inflammation can provoke the production of monocyte tissue factor, stimulate hyperreactivity of platelet, promote biosynthesis of fibrinogen, and enhance formation of the microparticle and erythrocyte aggregability, thus agitate prothrombotic state.(29) Present study demonstrated a significant increase of $0.9 \mathrm{mg} / \mathrm{L}$ of post-exercise hs-CRP level over the baseline.
A study in Turkey reported that after exercise stress test there was a significant increase of $0.5 \mathrm{mg} / \mathrm{L}$ of post-exercise stress test hs-CRP level over the baseline in subjects with obstructive coronary lesions, while there was no increase in subjects without obstructive coronary lesions.(31)

The study in Turtu concluded exercise induced a significant increment in inflammatory markers i.e., white blood count, hs-CRP, IL-6, IL-10 and MCP-1 concentrations. The long-distance sculling intensity variables such as the average rating of perceived exertion, HR and blood lactate were correlated with changes in IL-8, IL- $1 \alpha$ and IL- $1 \beta$ levels. Maximal aerobic performance variables (maximum rate of oxygen consumption ( $\mathrm{VO} 2$ max) and maximal aerobic power) were related to changes in IL-2, IL-4, IL-8 and IL-1 $\beta$ levels.(30) It was also clearly stated in a systematic review that acute moderate and heavy physical exercise influences in the elevation of pro-inflammatory i.e., IL-6, TNF- $\alpha$, IL-8 and hs-CRP and lowering the anti-inflammatory markers i.e., IL-1, IL-10 and adiponectin, while regular moderate physical exercise will make favorable effects in lowering pro-inflammatory markers and increasing anti-inflammatory markers.(29)

The current study also showed that exercise intensity significantly influenced the magnitude of post-exercise hs-CRP elevations. This finding is in accordance with an American study reporting that hs-CRP elevations were directly linked to exercise intensity.(32) We also found

Table 4. Regression logistic model for post-exercise hs-CRP elevation.

\begin{tabular}{lcccc}
\hline \multicolumn{1}{c}{ Variables } & $\boldsymbol{\beta}$ & OR adjusted & $\mathbf{9 5 \%} \mathbf{C I}$ & $\boldsymbol{p}$ \\
\hline BMI & 0.216 & 1.241 & $1.043-1.476$ & 0.015 \\
Age & 0.034 & 1.034 & $0.989-1.082$ & 0.137 \\
Cycling distance & -1.527 & 0.217 & $0.062-0.758$ & 0.017 \\
Constant & -6.806 & & & 0.007 \\
\hline
\end{tabular}


that cycling distance was related to post-exercise hs-CRP elevations. The training status or training volume of these subgroups may be responsible for these findings as a previous study found these characteristics to be predictive for changes in hs-CRP levels following exercise.(32) We also must take notice that training volume influences to the exercise intensity, as seen in this study, NC240K group had relative higher training volume and adapted longer duration and distance with lower exercise intensity than other groups. Similar results were found in both of these studies, however, the present study just evaluated hs-CRP while the previous study measured almost whole pro- and anti-inflammatory markers such as interferon- $\gamma$, IL-1b, IL-2, IL-8, IL-10 and IL-12p70, and granulocyte and monocyte phagocytosis (GR-PHAG and MO-PHAG).

\section{Conclusion}

In endurance cyclists, this study confirmed that body mass, BMI, waist circumference and lipid levels (total- and HDL-cholesterol) were associated with baseline hs-CRP levels, while BMI and cycling distance were associated with post-exercise hs-CRP elevations. Further research is needed to elucidate exercise-induced changes in pro- and anti-inflammatory biomarkers and to unravel the underlying mechanisms that are responsible for these responses.

\section{Acknowledgements}

Research was funded by the Directorate of Research and Public Service, Ministry of Research, Technology and Higher Education of the Republic of Indonesia (DIPA 042.06.1.401516). The authors would like to thank all the investigators and organizers of 2017 Indonesia North Coast and Tour de Borobudur cycling tours, and all the study participants.

\section{References}

1. Yousuf O, Mohanty BD, Martin SS, Joshi PH, Blaha MJ, Nasir K, et $a l$. High-sensitivity C-reactive protein and cardiovascular disease: A resolute belief or an elusive link? J Am Coll Cardiol. 2013; 62: 397-408.

2. Shrivastava AK, Singh HV, Raizada A, Singh SK. C-reactive protein, inflammation and coronary heart disease. Egypt Hear J. 2015; 67: 89-97.

3. Kasapis C, Thompson PD. The effects of physical activity on serum C-reactive protein and inflammatory markers: a systematic review.
J Am Coll Cardiol. 2005; 45: 1563-9.

4. Fallon KE. The acute phase response and exercise: The ultramarathon as prototype exercise. Clin J Sport Med. 2001; 11: 38-43.

5. Andersson J, Jansson JH, Hellsten G, Nilsson TK, Hallmans G, Boman K. Effects of heavy endurance physical exercise on inflammatory markers in non-athletes. Atherosclerosis. 2010; 209: 601-5.

6. Nunes RAB, Araújo F, Correia GF, Da Silva GT, Mansur AJ. Highsensitivity C-reactive protein levels and treadmill exercise test responses in men and women without overt heart disease. Exp Clin Cardiol. 2013; 18: 124-8.

7. Eijsvogels TMH, Fernandez AB, Thompson PD. Are there deleterious cardiac effects of acute and chronic endurance exercise? Physiol Rev. 2016; 96: 99-125.

8. Stanojevic D, Jakovljevic V, Barudzic N, Zivkovic V, Srejovic I, Parezanovic Ilic K, et al. Overtraining does not induce oxidative stress and inflammation in blood and heart of rats. Physiol Res. 2016; 65: 81-90.

9. Tidball JG. Inflammatory processes in muscle injury and repair. Am J Physiol Regul Integr Comp Physiol. 2005; 288: 345-53.

10. Peake JM, Suzuki K, Wilson G, Hordern M, Nosaka K, MacKinnon $\mathrm{L}$, et al. Exercise-induced muscle damage, plasma cytokines, and markers of neutrophil activation. Med Sci Sports Exerc. 2005; 37: 737-45.

11. Wallberg L, Mikael Mattsson C, Enqvist JK, Ekblom B. Plasma IL-6 concentration during ultra-endurance exercise. Eur J Appl Physiol. 2011; 111: 1081-8.

12. Skadberg Ø, Kleiven Ø, Bjørkavoll-Bergseth M, Melberg T, Bergseth $\mathrm{R}$, Selvåg $\mathrm{J}$, et al. Highly increased Troponin I levels following high-intensity endurance cycling may detect subclinical coronary artery disease in presumably healthy leisure sport cyclists: The North Sea Race Endurance Exercise Study (NEEDED) 2013. Eur J Prev Cardiol. 2017; 24: 885-94.

13. Bessa AL, Oliveira VN, Agostini GG, Oliveira RJS, Oliveira ACS, White GE, et al. Exercise intensity and recovery: biomarkers of injury, inflammation, and oxidative stress. J Strength Cond Res. 2016; 30: 311-9.

14. Mouridsen MR, Nielsen OW, Carlsen CM, Mattsson N, Ruwald MH, Binici Z, et al. High-sensitivity C-reactive protein and exerciseinduced changes in subjects suspected of coronary artery disease. J Inflamm Res. 2014; 7: 45-55.

15. Tanaka H, Monahan KD, Seals DR. Age-predicted maximal heart rate revisited. J Am Coll Cardiol. 2001; 37: 153-6.

16. Ridker PM. High-sensitivity c-reactive protein, potential adjunct for global risk assessment in the primary prevention of cardiovascular disease. Circulation. 2001; 103: 1813-8.

17. Arbel Y, Birati EY, Shapira I, Finn T, Berliner S, Rogowski O. Comparison of different anthropometric measurements and inflammatory biomarkers. Int $\mathrm{J}$ Inflam. 2012; 2012: 1-5. doi: 10.1155/2012/124693.

18. Zarzeczny R, Nawrat-Szołtysik A, Polak A, Manasar A, Maliszewski J, Kieltyka A, et al. The relationship between selected body fatness indices and the level of blood interleukin- 6 in female nursing home residents aged $80+$ years without inflammation: A pilot study. Exp Gerontol. 2018; 108: 240-6.

19. Sigdel M, Kumar A, Gyawali P, Shrestha R, Tuladhar ET, Jha B. Association of high sensitivity C-reactive protein with the components of metabolic syndrome in diabetic and non-diabetic individuals. J Clin Diagnostic Res. 2014; 8: 11-3.

20. Samad F, Ruf W. Inflammation, obesity, and thrombosis. Blood. 2013; 122: 3415-22.

21. Izaola O, de Luis D, Sajoux I, Domingo JC, Vidal M. Inflammation and obesity (Lippoinflammation). Nutr Hosp. 2015; 31: 2352-8. 
22. Sponder M, Kopecky C, Campean IA, Emich M, Fritzer-Szekeres M, Litschauer B, et al. Sports and HDL-quality reflected by serum amyloid A and surfactant protein B. Int J Med Sci. 2017; 14: 1040-8.

23. Tsao TH, Yang C Bin, Hsu CH. Effects of different exercise intensities with isoenergetic expenditures on C-reactive protein and blood lipid levels. Res Q Exerc Sport. 2012; 83: 293-9.

24. Rehnuma B, Hassan Z, Ibrahim M, Ali L. Serum levels of high sensitivity C-Reactive protein and its association with lipidemic status in Bangladeshi healthy adults. J Pathol Nepal. 2014; 4: 644-8.

25. Sponder M, Campean IA, Emich M, Fritzer-Szekeres M, Litschauer $\mathrm{B}$, Bergler-Klein J, et al. Long-term endurance training increases serum cathepsin S and decreases IL-6 and hsCRP levels. J Sports Sci. 2017; 35: 2129-34.

26. Zelzer S, Tatzber F, Herrmann M. Work intensity, low-grade inflammation, and oxidative status: a comparison between office and Slaughterhouse Workers. Oxid Med Cell Longev. 2018; 2018: 2737563. doi: 10.1155/2018/2737563.

27. Fernandes RA, Ritti-Dias RM, Balagopal PB, Conceição RDO, Santos RD, Cucato GG, et al. Self-initiated physical activity is associated with high sensitivity C-reactive protein: A longitudinal study in 5,030 adults. Atherosclerosis. 2018; 273: 131-5.

28. McFarlin BK, Flynn MG, Campbell WW, Craig BA, Robinson JP, Stewart LK, et al. Physical activity status, but not age, influences inflammatory biomarkers and toll-like receptor 4. J Gerontol A Biol Sci Med Sci. 2006; 61A: 388-93.

29. Chen YW, Apostolakis S, Lip GYH. Exercise-induced changes in inflammatory processes: Implications for thrombogenesis in cardiovascular disease. Ann Med. 2014; 46: 439-55.

30. Jurimae J, Tillmann V, Purge P, Jurimae T. Acute inflammatory response to prolonged sculling in competitive male rowers. J Sport Med Phys Fit. 2016; 56: 1368-75.

31. Basar N, Saatci Yasar A, Erden G, Cagli K, Sen N, Metin F, et al. The relation between exercise- induced myocardial ischemia and highsensitive C-reactive protein and neopterin levels. Anadolu Kardiyol Derg. 2010; 10: 502-7.

32. Nieman DC, Konrad M, Henson DA, Kennerly K, Shanely RA, Wallner-Liebmann SJ. Variance in the acute inflammatory response to prolonged cycling is linked to exercise intensity. J Interf Cytokine Res. 2012; 32: 12-7. 